\title{
FILOSOFÍA DE (PARA) LA CONQUISTA. EUROCENTRISMO Y COLONIALISMO EN LA DISPUTA POR EL NUEVO MUNDO ${ }^{1}$
}

\section{PHILOSOPHY OF (FOR) THE CONQUEST. EUROCENTRISM AND COLONIALISM IN THE DISPUTE FOR THE NEW WORLD}

\section{JOSÉ SANTOS HERCEG ${ }^{2}$}

\section{RESUMEN}

El objetivo de este escrito es demostrar que tanto la discusión "acerca" de la conquista de América -conocida como "filosofía de la Conquista"-como la reflexión de los más famosos pensadores que participaron en el debate -Juan Ginés de Sepúlveda, Francisco de Vitoria y Bartolomé de las Casas- se caracteriza por ser eurocéntrica y colonialista. Esta es la razón por la cual sería preferible en este caso hablar de una filosofía "para" la conquista, en lugar de una filosofía "de" o "acerca" de la Conquista.

Palabras clave: Conquista, América Latina, eurocentrismo, colonialismo.

\section{ABSTRACT}

This paper aims to demonstrate that the discussion "about" the Conquest of America -known as the Philosophy of the Conquest-as well as the reflections of the most famous thinkers who participated in the debate -Juan Ginés de Sepúlveda, Francisco de Vitoria and Bartolomé de las Casas- can be characterized as being eurocentric and colonialist. This is the reason why it would be preferable to speak of a philosophy "for" the conquest instead of a philosophy "of" or "about" the conquest.

Keywords: Conquest, Latin America, eurocentrism, colonialism.

Recibido: 23.04.10. Aceptado: 28.08.10.

${ }^{1}$ Este artículo ha sido desarrollado en el marco del proyecto Fondecyt 1080017.

${ }^{2}$ Licenciado en Filosofía (Universidad Católica de Chile), Dr. en Filosofía (Universidad de Konstanz, Alemania). Docente en el Instituto de Estudios Avanzados (IDEA), Universidad de Santiago de Chile (USACH). Santiago, Chile. E-mail: jose.santos@usach.cl 
LOS pocos años del "descubrimiento" de América comienzan a hacerse evidente -de eso es fiel testimonio el famoso "Sermón de Montecinos" (1511) - que los españoles cometen excesos, que simplemente abusan de los habitantes originarios del continente. “(...) [t]odos estáis en pecado mortal y en él vivís y morís, por la crueldad y tiranía que usáis con estas inocentes gentes", sentencia Montecinos, a lo cual agrega dos preguntas: “¿Con qué derecho y con qué justicia tenéis en tan cruel y horrible servidumbre a estos indios? ¿Con qué autoridad habéis hecho tan detestables guerras a estas gentes que estaban en sus tierras mansas y pacíficas, donde tan infinitas de ellas, con muertes y estragos nunca oídos, habéis consumido?". En estas dos cuestiones se encuentra el germen de los dos grandes problemas filosóficos a que da lugar la conquista de América: un problema de orden moral-antropológico y otro de carácter filosóficopolítico.

La primera cuestión se refiere, como es evidente, al asunto de la esclavitud. Ésta es la que primero surge dada la impresionante e indesmentible realidad del maltrato, del abuso. Montecinos, de hecho, esboza ya el meollo del asunto discutido, cuando acentúa: "Estos, ¿no son hombres? ¿No tienen ánimas racionales?"3. La segunda cuestión se relaciona con la licitud de la guerra de conquista y surge, sin duda, de la primera. Aunque la preocupación por el asunto de la esclavitud prima durante la parte inicial del siglo XVI, será la segunda, en tanto que fundamento de una posible respuesta a la primera, la que finalmente ocupará el centro de la reflexión. Son estas inquietudes de Montecinos las que dan lugar a lo que Silvio Zabala llamó "filosofía de la conquista".

Para Zabala esta "filosofía de la conquista" es “(...) una filosofía política en contacto con problemas vivos, de penetración y asiento en las nuevas tierras" (1994: 21). Se trataría, por lo tanto, de una reflexión cuyo tema, cuyo asunto, es una serie de problemas que se desprenden del hecho de la conquista. Filosofía de la conquista sería, en este sentido, una "filosofía acerca de la conquista". Un pensamiento que se hace cargo de los problemas que surgen de dicho proceso -puntualmente los de carácter político- e intenta buscarles una solución. Lo hace, hay que tenerlo presente, exclusivamente con elementos teóricos que, como lo hace ver el mismo Zabala, "provenían de Europa” (20). Filosofía política europea que busca hacerse cargo de la situación americana. Incluso los pensadores que participan de la discusión

\footnotetext{
${ }^{3}$ No se conservan los textos autógrafos de los sermones. Sólo se conocen mediante un resumen que consigna fray Bartolomé de las Casas en su Historia de las Indias (1957, caps. 3-5).
} 
son todos europeos y, en algunos casos, ni siquiera llegan a pisar América, como Juan López de Palacios Rubios, Juan Ginés de Sepúlveda y Francisco de Vitoria ${ }^{4}$. No participa en esta discusión, bajo ninguna forma, representante alguno del mundo indígena. Ellos, que evidentemente tenían interés en el asunto $y$, sin duda, habrían aportado con una postura alternativa a la disputa, no son tomados en cuenta de ninguna forma. Habrá que esperar a que Miguel León-Portilla compile y publique bajo el nombre de La visión de los vencidos algunos escritos indígenas, para que se diera a conocer la postura de los habitantes originarios acerca del tema de la conquista. Este libro se publica, sin embargo, recién en 1959, más de cuatro siglos y medio después del primer desembarco español.

Por otra parte, la llamada "filosofía de la conquista" no es una reflexión filosófica realmente pura, sino que en ella se entremezclan argumentos propiamente filosóficos con otros de orden teológico. Esta mezcolanza tiene su origen en la entrada misma del Nuevo Mundo a la cosmovisión española. Es necesario no perder de vista, tal como hace ver Fernando Mires, que dado el contexto de la Reconquista y la expulsión de los infieles “(...) el descubrimiento de América no podía sino ser considerado como un acto milagroso de acuerdo con el cual Dios premiaba a los Reyes de España por sus servicios a la causa cristiana" (2006: 41). El Nuevo Mundo es percibido como una "recompensa" de un Dios justo que habría de compensar las pérdidas y dolores sufridos en nombre de la Iglesia. La nueva tierra adquiere caracteres de tierra prometida, tierra santa, paraíso perdido para los clérigos. Para los conquistadores, sin embargo, es un espacio plagado de oro y plata, de riquezas sin límite que explotar y saquear, de hombres que esclavizar. Como ha hecho ver muy acertadamente Mires, aunque la espada y la cruz fueron clavadas al mismo tiempo en la tierra americana, la espada, no obstante, requería de la cruz para justificarse (2006: 40-53). Dicha justificación tenía que ver con hacer aparecer la conquista en general y cada campaña ${ }^{5}$ en particular como indispensable para la misión evangelizadora, para la tarea misional. La necesidad de una justificación misional tiene su origen en el hecho de que la propiedad de España sobre las tierras descubiertas provenía de la autoridad papal. No debe olvidarse que América le

\footnotetext{
${ }^{4}$ Existen, sin embargo, otros autores que han sido llamados “indianos", es decir, europeos con experiencia en ultramar, como Bartolomé de las Casas y José de Acosta. Interesante es anotar en este punto que, según Zavala, “(...) es perceptible cierta diferencia -muy comprensible según élentre el pensamiento de unos y otros" (20).

5 "Afirmamos: para el propio cumplimiento de sus tareas militares los conquistadores no podían prescindir de los cléricos pues, sin ellos a su lado, las guerras a los indios habrían aparecido como lo que eran: vulgares depredaciones" (Mires, 2006: 48).
}

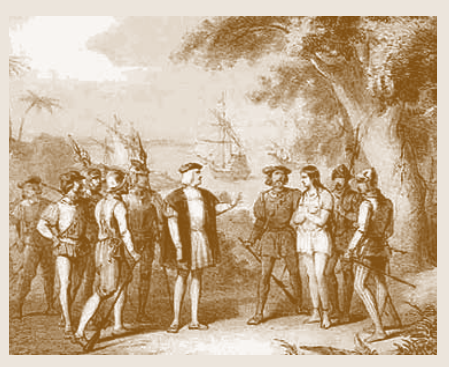


fue adjudicada a España por una Bula de Alejandro VI. La "filosofía de la conquista" es, al mismo tiempo, una "filosofía de la evangelización".

La "filosofía de la conquista" es un reflexión neta y exclusivamente europeo-occidental, hecha por europeos y mezclada -por no decir revueltacon asuntos y argumentos de orden teológico-misional. En ella, como es evidente, es posible encontrar posiciones diferentes, incluso antagónicas ${ }^{6}$. Todas ellas comparten, no obstante, una idea de base: que los indígenas deber ser incorporados -se discute si violenta o pacíficamente- al mundo europeo, a su cosmovisión, a su religión: que deben ser civilizados; evangelizados. Ni la corriente más extremamente esclavista e imperialista, como es evidente, pero tampoco la visión indigenista eran, de hecho, anticolonialistas 7 . Juan Friede señala, por eso mismo, que de haber triunfado la corriente indigenista, “(...) hubiera convertido al indio, siervo de hecho, en un libre vasallo de la Corona (...)" (1974: 27). El destino de vasallaje, de subordinación de los indígenas al imperio, nunca estuvo realmente en discusión. La "filosofía de la conquista" se para sobre la base incuestionada de una cosmovisión dicotómica: centro y periferia, o, como se expresará en la discusión misma, prudentes-bárbaros y cristianos-infieles. La discusión en general tendrá de fondo, como bien lo vio Lewis Hanke, un solo gran tema: la "capacidad o incapacidad de los indios para vivir como los españoles" (1967: 81), de los bárbaros para ser civilizados, de los infieles para convertirse en cristianos. Incluso la pregunta por su "humanidad" - ¿son hombres los indios?- debe entenderse, de acuerdo con Enrique Dussel, en el sentido de “ison europeos y por ello animales racionales?” (1977: 12). La sobrevaloración del modo de vida español y la minusvaloración de la de los habitantes originarios de América salta a la vista: la duda acerca de la capacidad de los indios es una pregunta por las condiciones de posibilidad de su ascenso, de su mejoramiento, de su europeización.

La "filosofía de la conquista" no es, por lo tanto, una simple "disputa acerca del nuevo mundo". Es, en realidad, como se intentará demostrar, un intento por fundamentar la legitimidad del dominio español sobre las Indias, por justificar el gesto radical e indetenible de hacer de América otra

\footnotetext{
${ }^{6}$ Fernando de Mires ha hablado de que durante el período de la conquista habrían existido fundamentalmente tres posturas en disputa: una claramente imperialista o esclavista cuyo mayor ideólogo fue Juan Ginés de Sepúlveda, una eminentemente anti-esclavista o indigenista cuya voz más sobresaliente fue la de Bartolomé de las Casas y una intermedia, llamada también "centrista", caracterizada por la opinión de autores como fray Pedro Mexía y fray Toribio de Montolinia.

7 “(...) creemos aquí que la corriente indigenista no era necesariamente anticolonialista, sino que se basa en otro tipo de sujeción colonial que no deriva de la esclavitud de la fuerza (...)" (Mires, 2006 138).
} 
España. Desde esta perspectiva la "filosofía de la conquista" es eminentemente una filosofía hegemónica, una filosofía "para" la conquista. Juan Ginés de Sepúlveda, Francisco de Vitoria y Bartolomé de las Casas, quizás los más grandes y, sin duda, los más famosos teóricos de la filosofía de la conquista, aunque tienen posturas en muchos sentidos diferentes y en algunos claramente antagónicas, tienen en común, sin embargo, el eurocentrismo y el colonialismo; el convencimiento de la superioridad europeo-cristiana y de una inferioridad de los indígenas para los cuales el camino de la colonización y la evangelización es un ascenso, un evidente mejoramiento, la ruta hacia la civilización y el reino de Dios.

\section{INFERIORIDAD NATURAL}

Juan Ginés de Sepúlveda ha pasado a la posteridad por haber sido el gran defensor de la "servidumbre natural" de los indios (1996 [1567]: 47). Lo particular de este autor radica fundamentalmente en que no se trata de un teólogo, ni su análisis nace de la teología que dominaba el debate en la época que sigue al descubrimiento y conquista del Nuevo Mundo. El prestigioso jurista intentó desarrollar una argumentación racional, y en virtud de ella pretendió, según su propia confesión, haber mostrado “(...) con sólidas y evidentísimas razones (...) la justicia de nuestro imperio" (47). Como se verá, el "nuestro" de esta afirmación debe entenderse como un "de nosotros los españoles", y el término "imperio" hay que leerlo en el sentido de "tener dominio sobre otras gentes", que aquí son, evidentemente, los indígenas del Nuevo Mundo. Lo que pretende haber demostrado Sepúlveda es, por lo tanto, la justicia del dominio de los españoles sobre las tierras y los habitantes de las Indias, y las "razones" tan "sólidas y evidentísimas" a las que el autor hace referencia tienen que ver con el hecho "indesmentible" de que los habitantes de este Mundo Nuevo eran "bárbaros".

El ser "bárbaros" de los indígenas -nombre con que Sepúlveda se refiere a ellos siempre ${ }^{8}$ - se pone de manifiesto según el autor en dos cosas: su "torpeza de entendimiento" y sus "costumbres inhumanas" (82-83). Sostendrá que estos "hombrecillos" -nombre que también utiliza para hablar de los indios-, por una parte, carecen de cultura, de ciencia, de escritura, de

\footnotetext{
${ }^{8}$ Nótese en este punto que al usar esta denominación Sepúlveda presupone justamente aquello que debería probar, esto es, que los indígenas era "bárbaros". Lo hace, sin duda, porque lo considera un factum incontrastable, pero, como veremos, toda su argumentación en favor de la "esclavitud" se basa sobre este presupuesto.
}

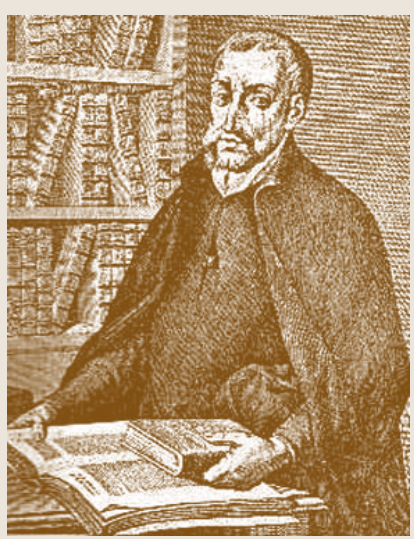

J.G. de Sepúlveda 
historia, no tienen leyes escritas, lo que demuestra su falta de racionalidad (105-113) y, por otra parte, son antropófagos, hacen sacrificios humanos, tienen cultos impíos a ídolos, lo que prueba que sus costumbres son inhumanas(133). En esta falta de racionalidad, con su consecuente inferioridad natural, $y$ en sus atentados contra la ley natural, testimonios de su evidente barbaridad, encontrará Ginés de Sepúlveda dos de sus principales argumentos para justificar la conquista. Porque son torpes de entendimiento se les considera inferiores y por ello determinados por naturaleza a estar al servicio de otros: los superiores, los racionales ${ }^{9}$. Porque sus costumbres son inhumanas y atentan sistemática e impunemente ${ }^{10}$ contra la ley natural ${ }^{11}$ es necesario hacerles la guerra y conquistarlos. A estas naciones, dice el autor, “(...) podrían con pleno derecho los cristianos, si rehúsan someterse a su imperio, destruirlas por sus nefastos delitos y barbarie e inhumanidad" $(125)^{12}$.

Lo "prudente" de los españoles, por su parte, es la razón por la cual son ellos los llamados a constituirse en los señores de los indígenas. La apología que hace Ginés de Sepúlveda de los españoles, sin que se pretenda desconocer las virtudes de este pueblo, raya definitivamente en el ridículo ${ }^{13}$. Según él, ensalza y eleva a los españoles el que posean figuras culturalmente excelsas, su gran poder bélico, y las virtudes de la templanza, la frugalidad, la sobriedad, la fortaleza, la prudencia, el ingenio, la mansedumbre y la religiosidad acompañada de sentimientos humanitarios. La conclusión es, por lo tanto, “(...) que con perfecto derecho los españoles imperan sobre estos bárbaros del Nuevo Mundo e islas adyacentes, los cuales en prudencia, ingenio, virtud y humanidad son tan inferiores a los españoles" (101-102). Es más, lo mejor que les puede ocurrir a los bárbaros será, a su juicio, el ser

9 “El que es necio servirá al sabio. Tales son las gentes bárbaras e inhumanas, (...) Y será siempre justo y conforme al derecho natural que tales gentes se sometan al imperio de príncipes y naciones más cultas y humanas" (85).

10 "Pero si hubiese una gente tan bárbara e inhumana que no contase entre las cosas torpes todos o algunos de los crímenes que he enumerado y no los castigase en sus leyes y en sus costumbres o impusiese penas levísimas a los más graves y especialmente a aquellos que la naturaleza más detesta, de esa nación se dirá con toda justicia y propiedad que no observa la ley natural" (121-125).

11 "No es doctrina temeraria pues, sino muy racional y enseñada por varones erudísimos y por la autoridad del sumo pontífice, el ser lícito a los cristianos perseguir a los paganos y hacerles la guerra si no observan la ley natural, como pasa en lo tocante al culto de los ídolos" (121-123).

12 "Y si rehúsan nuestro imperio, podrán ser compelidos por las armas a aceptarle, y será esta guerra (...) justa por ley de la naturaleza”(135).

${ }^{13}$ Fernando Mires ha puesto de manifiesto que el nacionalismo de Sepúlveda "(...) no conoce límite y por momentos adquiere un peligroso carácter militarista" y lo califica de "fanático hispanista" (2006: 78). 
conquistados por los españoles ${ }^{14}$, e insiste, una y otra vez, en el hecho de que los mayores beneficiados con la conquista son los indianos, pues “(...) la virtud, la humanidad y la verdadera religión son más preciosas que el oro y que la plata" (135).

Hay dos cuestiones que saltan a la vista en la argumentación de Sepúlveda. Por una parte, su dependencia evidente y no disimulada de la reflexión de Aristóteles. Por otra parte, su extremado y tampoco oculto eurocentrismo, o hispanocentrismo más bien. Ambos asuntos, por supuesto, están claramente vinculados: en la reflexión aristotélica hay rasgos de un helenocentrismo evidente. En efecto, Aristóteles fue un claro partidario de la "esclavitud"; así lo evidencian algunos pasajes de la primera parte de su Política. Allí es donde señala que, "está claro que unos son libres y otros esclavos por naturaleza, y que para éstos el ser esclavos es conveniente y justo" (1254b27- 1255a-2). Del mismo modo, Aristóteles era un convencido partidario de la "colonización", pues, como él mismo señala citando al poeta, "justo es que los helenos manden sobre los bárbaros" (1252b3-4). El asunto se zanja rápidamente, pues, “(...) de nacimiento -señala- algunos están destinados a obedecer y otros a mandar" (1254a2). El fundamento último de sus afirmaciones lo encuentra el filósofo, tal como lo hará siglos después Gines de Sepúlveda siguiendo su ejemplo, en la naturaleza. Es en ella donde está el origen de las diferencias: unos mandan por naturaleza y otros son súbditos por la misma razón ${ }^{15}$. Tan natural es la distinción y jerarquización que, de hecho, lo más "conveniente y justo" que le puede pasar al dominado es ser dominado y al dominante, el dominar ${ }^{16}$.

El helenocentrismo de Aristóteles se pone en evidencia en estos pasajes de su Política, del mismo modo como el eurocentrismo o hispanocentris-

14 “¿Qué cosa pudo suceder a estos bárbaros más conveniente ni más saludable que el quedar sometidos al imperio de aquello cuya prudencia, virtud y religión los han de convertir de bárbaros, tales que apenas merecían el nombre de seres humanos, en hombres civilizados en cuanto pueden serlo; de torpes y libidinosos, en probos y honrados; de impíos y siervos de los demonios, en cristianos y adoradores del verdadero Dios?” (Ginés de Sepúlveda, 1996: 133).

15 "En efecto, en todo lo que consta de varios elementos y llega a ser una unidad común, ya de elementos continuos o separados, aparecen siempre el dominante y el dominado, y eso ocurre en cuanto pertenecen al conjunto de la naturaleza" (1254a-4).

16 "De éstos, para uno, es conveniente y justo ser esclavo, y para otro, dominar, y uno debe obedecer y otro mandar con la autoridad de que la naturaleza le dotó, y por tanto, también dominar" (1255b-9-10). Esta opinión será matizada más adelante cuando sostenga que hay distintas clases de autoridad y que si bien es cierto la que se ejerce sobre la mujer se haga "(...) esencialmente en interés de los gobernados (...)" (1278b7). En el caso de los esclavos es diferente. "La autoridad del amo, aunque haya en verdad un mismo interés para el esclavo por naturaleza y para el amo por naturaleza, sin embargo no menos se ejerce atendiendo a la conveniencia del amo, y sólo accidentalmente a la del esclavo (...)” (1278b6). 
mo de Ginés de Sepúlveda impregna toda su argumentación. Una España superior, céntrica, depositaria de todo tipo de virtudes, cuasi perfecta en relación con la cual todo pueblo es pobre, vicioso, opaco. El Nuevo Mundo y sus habitantes están en las antípodas de los españoles: pobres, retrasados, idólatras, simplemente insignificantes, despreciables. Nótese, por ejemplo, los parámetros que utiliza para "demostrar" la irracionalidad de los indígenas: carecen de ciencia, de escritura, de historia, no tienen leyes escritas. Todas estas son marcas propias de la cultura europea, que se considera el paradigma de perfección. En el contexto de los etnocentrismos la disparidad sería suficiente argumento para justificar una invasión, una conquista, una guerra. Ya lo había dicho el mismo Aristóteles: "Por eso el arte de la guerra será en cierto modo un arte adquisitivo por naturaleza (el arte de la caza es una parte suya) y debe utilizarse contra los animales salvajes y contra aquellos hombres que, habiendo nacido para obedecer, se niegan a ello, en la idea de que esa clase de guerra es justa por naturaleza"17.

$\mathrm{El}$ aristotelismo y etnocentrismo que se percibe en la argumentación de Sepúlveda son también características que están presentes en los textos de sus más connotados y famosos críticos: Francisco de Vitoria y Bartolomé de las Casas. Es más, los propios contra-argumentos de estos autores demuestran que, de hecho, la estructura argumental de Sepúlveda está plenamente justificada. Dicho de otra forma, tanto Vitoria como Las Casas siguen siendo aristotélicos, eurocéntricos y colonizadores: en sus argumentos en contra de Sepúlveda es posible observar que lo fundamental del pensamiento de Aristóteles sigue estando justificado y permanece incuestionado y que, por lo tanto, ellos son, en sus propios razonamientos, etnocéntricos y dominadores.

\section{A. Irracionalidad e inferioridad}

En la postura de Sepúlveda cristaliza una larga tradición de pensadores que sostuvieron, antes que él, ideas que apuntaban en la misma dirección. La irracionalidad de los indios había sido utilizada como argumento en favor de la conquista y esclavitud; por ejemplo, ya en 1524 por fray Tomás Ortiz, quien, entre otras cosas, dice de los indios que "son como asnos, abobados, alocados, insensatos" (López, 1941: 242). A raíz de ello es que, aunque parezca sorprendente, cuando Ginés de Sepúlveda sostenía esta postura,

\footnotetext{
${ }^{17} 1256 b-12$ [67].
} 
hacía ya años que había sido puesta en cuestión por Francisco de Vitoria, quien en 1538-39 sostuvo la tesis de que pese a que los bárbaros -también utiliza esta denominación- están en una posición desmedrada y “(...) se diferencian muy poco de los dementes", sin embargo, “ (...) no están totalmente faltos de juicio" (1998: 148). Esta posición la fundaba en el hecho de que "no son dementes sino que a su manera tienen uso de razón" (82). Algo racionales, aunque no prudentes del todo, para Vitoria los habitantes originarios de América siguen siendo "bárbaros". El origen de dicha barbaridad no radica, sin embargo, en la naturaleza, sino en una "mala y bárbara educación”, lo que lo distancia del argumento de Sepúlveda. Para Vitoria es, por lo tanto, "dudoso" un título de conquista basado en aquel "principio de caridad", esto es, en la conveniencia -ya no necesidad- de someter a los bárbaros a la tutela de algún "superior". Este autor se da cuenta, además, de que este fundamento se sostiene simplemente sobre la base de "la rudeza que les atribuyen los que han estado allí" (149). Recordemos que ni Vitoria ni Sepúlveda pisan nunca las Indias y toda su información es de oídas; pero al menos en el primero, a diferencia del segundo, se percibe un reconocimiento de los límites de su juicio a causa de ello.

Quien no tiene informes indirectos sino de primera fuente es Bartolomé de las Casas. Para él los indígenas no son sólo racionales, sino que, como dice en su tratado Del único modo de atraer a todos los pueblos a la verdadera religión, "todos ellos están dotados de verdadero ingenio" (1942:3), o, como destaca en la Brevísima relación de la destrucción de Indias, "son (...) vivos de entendimiento, muy capaces" (1999: 76). Nada de irracionales tienen los indígenas según el juicio de Las Casas. El objetivo esencial de todo el trabajo del fraile será de hecho, como bien ha escrito Todorov, mostrar que ninguna de las costumbres o de las prácticas de los indios prueba que sean inferiores (1992: 177). La historia se vuelve, por lo tanto, para este autor, Apología. Sus escritos pueden ser leídos como una gran defensa de los indígenas y una denuncia de la injusticia de los conquistadores. Negada la irracionalidad e inferioridad de los indios, ni la conquista ni la consecuente esclavitud están justificadas, al menos en virtud de este título.

Hay que hacer notar, sin embargo, que por loable que sea la intención y los sentidos de estas argumentaciones de Vitoria y de Las Casas, ninguno de los dos discute el título de conquista y dominio esgrimido por Sepúlveda: lo que tanto Vitoria como Las Casas discuten es el simple hecho de que en el caso de los indios no se verifica. Para Vitoria “(...) si todos fueran dementes, no hay duda de que esto sería no solo lícito sino muy conveniente, y hasta estarían obligados a ello como si se tratara de simples niños" (1998: 148).

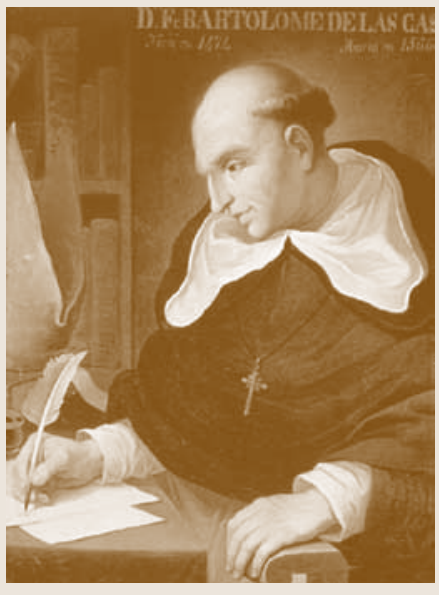

B. de las Casas 
La doctrina aristotélica de que lo inferior debe subordinarse a lo superior, en que se ampara la argumentación de Ginés de Sepúlveda, no es rebatida ni por Vitoria ni por Las Casas. Para estos autores ocurre simplemente que en el caso de los indios no puede hablarse propiamente de irracionalidad, demencia ni, por lo tanto, de una inferioridad tal que haga indispensable una conquista por la fuerza. Junto a Sepúlveda quedan atrapados sus críticos presa de los mismos prejuicios. Vitoria y Las Casas no rozan siquiera el fundamento argumental de Sepúlveda. La primera premisa, la premisa universal, queda intacta: los racionales -superiores- debe dominar a los faltos de razón -inferiores-. Sólo la segunda premisa, la particular, es puesta en duda: (tal vez) los indios no son irracionales. Aquí puede encontrarse el fundamento de aquella desafortunada y para algunos tan sorprendente defensa que hiciera en algún momento Las Casas de la esclavitud de los negros. El sacerdote no duda en afirmar que si se necesitan esclavos, debería dejarse en paz a los indios y traerlos de África. Como se ve, la esclavitud sigue estando justificada: los negros sí son irracionales, sí son inferiores ${ }^{18}$.

Junto a este aristotelismo algo oculto tras la argumentación de Vitoria y Las Casas, es posible observar también rasgos evidentes de etnocentrismo. Cuando Vitoria habla de la "inferioridad de los Indios se debe a su falta de educación, pues (...) no están totalmente faltos de juicio, (...) a su manera tienen uso de razón"(1998: 148), el parámetro de comparación es el juicio y la razón europeos. En un sentido diferente, pero con el mismo fundamento, cuando la apología que hace Las Casas alude a que los indios tienen "verdadero ingenio" (1942: 3) y que "son (...) vivos de entendimiento, muy capaces" (1999: 76), el criterio para sostenerlo es una vez más el ingenio y el entendimiento europeos. En ambos casos, ya sea para demostrar que no se está tan lejos o para establecer que se tiene el mismo nivel, lo europeo es utilizado como paradigma, como medida de perfección. Dicho de otra forma, para Vitoria no está justificada la conquista por esta vía, pues los indios, con la correcta educación, podrían llegar a tener un juicio y usar la razón tal como lo hiciera un europeo, y que para Las Casas no lo está, pues los indígenas poseen un ingenio y entendimiento del mismo nivel que el de los europeos. La sobrevaloración de lo europeo es evidentemente un rasgo característico del pensamiento de estos autores.

\footnotetext{
${ }^{18}$ Para ser justos hay que recordar que Las Casas se desdice de esta posición (Cf.: Mires, 2006: 172). Esto no quita, sin embargo, el hecho de que la sostuvo.
} 


\section{B. In-humanidad e in-fidelidad}

Sus costumbres son inhumanas, sus atentados contra la ley natural; en síntesis, los "pecados" de los indígenas deben ser castigados pues sus almas tienen que ser salvadas aunque sea por la fuerza ${ }^{19}$. Al igual que en el caso de la acusación de inferioridad por irracionalidad, el argumento de la necesidad de una conquista que ponga un punto final a los aberrantes pecados de los indios y, por lo tanto, tienda a la salvación de sus almas, precede a Ginés de Sepúlveda. Entre los autores que sostuvieron esta tesis se puede mencionar a Palacios Rubios, al licenciado Gregorio, a Alonso de Loaysa, a Barrios, a Martín de Valencia, a Soto, a Jiménez, a Reginaldo Morales y a Vicente de Santa María ${ }^{20}$. Incluso después de Sepúlveda algunos autores seguirán sosteniendo esta misma tesis para fundamentar la entrada por la fuerza contra los indios. Un ejemplo paradigmático lo constituye fray Pedro de Azuaga, obispo de Santiago de Chile, quien en 1596 sostenía que “(...) la ocupación violenta de Nueva España fue justa por la infidelidad y vicios de los naturales; era necesario castigar la injuria que éstos hacían a Dios con su apostasía. Se trataba de árboles infructuosos que habían de cortarse o quemarse" (Mires, 2006: 66). En el mismo sentido había escrito fray Juan Salmerón en 1584 a Felipe II: "Haber sido la guerra justa por razón de los bestiales pecados que estos indios tenían en destrucción de la naturaleza, matando y sacrificando hombres y por la mayor parte inocentes de lo cual siendo aconsejados y aprehendidos no queriendo enmendarse, pudieron con justo título ser conquistados" (Mires, 2006: 66).

Bartolomé de las Casas dirá al respecto, en primer término, y en un contexto general, que "todas estas universas e infinitas gentes a todo genero crió Dios las más simples, sin maldades ni dobleses (...) más humildes, más pacientes, más pacíficas y quietas, sin rencillas ni bollicios, no rijosos, no querulososo, sin rancores, sin odios, sin desear venganza, que hay en el mundo" (1999: 75, 76 y 1957). La Historia de las Indias puede, de hecho, concebirse como un intento por “(...) escribir íntegra la historia de los acontecimientos de las indias y mostrar cómo eran de verdad sus ha-

\footnotetext{
${ }^{19}$ Cabe hacer nota que el argumento de los atentados contra el derecho natural proveía en la práctica de un marco extraordinariamente amplio para la conquista, pues, como señala Fernando Mires, "cualquier señal de resistencia, cualquier gesto de rebelión podía ser visto como un pecado. Cualquier actividad que los indios hicieran podía ofender a Dios” (2006: 67).

${ }^{20}$ Cf.: García, 1984: 67-115. El mismo Francisco de Vitoria menciona entre quienes detentan esta tesis al Arzobispo de Florencia, a Agustín de Ancona, a Silvestre y a Inocencio (Cf.: 1998: 119).
}

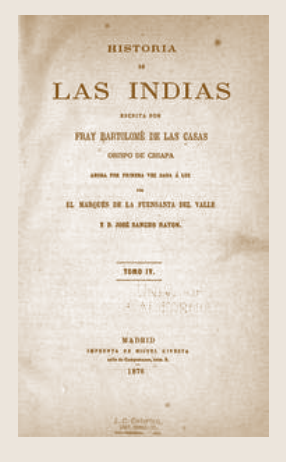


bitantes" (Pérez Tudela, 1957: CIX). El texto está plagado de alusiones a la mansedumbre y placabilidad de los indios, a la facilidad con que son atraídos a la fe y las buenas costumbres (Cf.: 1957: 158-159, 161, 163, 175, $183-84,269,271-272,275)$, a su bondad natural y simplicidad $(161,165$, $198,188-89,195,258-259,275,359)$, a su docilidad (171), su humanidad $(268,275)$, en síntesis, proponiendo que, como habría escrito Colón, “( ...) en el mundo creo que no hay mejor gente" (195). Alusiones que, las más de las veces, Las Casas refuerza con una nota al pie de página haciendo hincapié en las correspondientes virtudes. Este esfuerzo, por supuesto, cristaliza en la obra que lleva por nombre Apologética, cuya finalidad, de acuerdo con su autor es, justamente, mostrar que estas indianas gentes "son hombres, de naturaleza bien razonables y bien inclinados".

Las Casas se referirá a cada una de las imputaciones específicas de inhumanidades: antropofagia, sacrificios humanos, cultos impíos a ídolos. Acerca de la idolatría de los indios refiere el testimonio del mismo Colón, quien habría sostenido que “(...) no son idólatras" (171); que, al menos los indios de la Española, "jamás comieron carne humana ni tuvieron otras abominaciones que les han levantado" (176). Hay en Las Casas, en primer término, una negación de la existencia de atentados contra la ley natural entre los indígenas, y para sostener esta posición alude al testimonio de autoridad y a su propia experiencia, por lo que se fundamenta, en su mayor parte, una vez más, en la referencia a la realidad. Los indígenas no atentan contra la humanidad y si lo hacen es por ignorancia, pues su naturaleza es pura, transparente y están inclinados naturalmente hacia la bondad. De esta forma pretende desmantelar la argumentación de Sepúlveda desde su base empírica, pues ella se sostiene fundamentalmente en la obra de Fernández de Oviedo. Toda ella se sustentaba, según él, en información errada. Por ello dice que "Dios privó al doctor Sepúlveda de la noticia de todo esto".

Esta referencia a la "realidad" de una condición naturalmente "virtuosa" de los indígenas revela algunos problemas en la argumentación lascasiana ya antes aludidos. Por una parte, está el hecho ostensible de que la imagen de indígenas "virtuosos" que dibuja Las Casas está confeccionada de acuerdo con sus propios valores. En otras palabras, lo que trata de mostrar el dominico es que los indígenas americanos eran espontáneamente "buenos cristianos". La imagen idealizada de los indios presentada por Las Casas consiste, como ha señalado Todorov, en "identificar pura y simplemente al otro con el propio ideal del yo (o con el propio yo)". De allí se comprenden las virtudes "cristianas" atribuidas por doquier a los indígenas. El etnocentrismo de este gesto es evidente: no se les castigaría pues los indígenas son 
más cristianos que los propios cristianos. Con eso, por supuesto, no se desmantela en lo más mínimo el argumento de que se pueda hacer la guerra a quien atenta contra la ley natural, pues lo que se dice es, simplemente, que en este caso no se aplica. Al aludir a la virtud concreta de los indígenas, una vez más, no se desestabiliza el que a raíz de los atentados contra el derecho natural se pueda conquistar a un pueblo y someterlo por las armas en vistas de su propia salvación.

Las Casas admite, por lo demás, algunas situaciones límites en donde la referencia a la "realidad" pierde efectividad. En efecto, en algunos casos se ve en la necesidad de reconocer la existencia de "pecados imperdonables" por parte de los indígenas. En este contexto, sin embargo, niega nuevamente que ello otorgue un fundamento para una conquista, pero la razón que trae a colación, nuevamente, está lejos de atacar al argumento mismo. La guerra, señala el dominico, siempre es un mal mayor y por lo tanto siempre es más conveniente no llegar hasta ese límite. Con ello, lo que hace Las Casas es considerar que habría una falta de prudencia, una suerte de desproporción en cuanto a la consecuencia: hacer la guerra sería poco conveniente si lo que se pretende es castigar o alejar a los indígenas del pecado, es decir, salvarlos. Por sus pecados imperdonables habrían de ser castigados; sin embargo, la Guerra no es el medio adecuado para hacerlo, pues ésta sería un mal mayor. Una vez más el argumento de Sepúlveda permanece, pues lo único que se estaría alterando es que a causa de sus pecados los indígenas deben ser castigados -aunque el castigo debería ser otro-, deberían ser alejados del pecado para salvarlos -aunque la manera debería ser pacífica-.

El punto de Las Casas parece ser sólo un asunto de método: niega la viabilidad de la guerra y la esclavitud como camino para lograr la salvación de las almas de los indígenas. Sin ir más lejos, Las Casas sostendrá la idea de que el Nuevo Mundo es un antiquísimo e inagotable criadero de almas para el infierno (1957: 369). Almas que deben ser salvadas, pero no se consigue nada con la violencia, sino que sólo será posible mediante la evangelización, cristianización. La conversión debía ser ganada a través de "la persuasión del entendimiento por medio de razones y la invitación y la suave moción de la voluntad” (1942), pues, como señala, “(...) si tales verdades se propusieran con arrebato y rapidez; con alborotos repentinos y tal vez con el estrépito de las armas que respiran terror; o con amenazas o azotes, o con actitudes imperiosas y ásperas; o con cualquier otros modos rigurosos o perturbadores, cosa manifiesta es que la mente del hombre se consternaría de terror; que con la grita, el miedo y la violencia de las palabras, se conturbaría, se llenaría de aflicción y se rehusaría, de consiguiente, 
a escuchar (...)" (41). Nótese que lo que mueve a Las Casas a eliminar el uso de la violencia en la predicación son argumentos de carácter práctico: es poco eficiente. También Vitoria había previsto esta posibilidad: "Puede ocurrir que con estas guerras, matanzas y expolios más que promover y fomentar la conversión de los bárbaros se obstaculice" (1998: 142). Es por esto que, en vista de ciertas sospechas que tiene de lo que estaría ocurriendo de hecho en la práctica con los indios, advierte: "no sea que lo que de suyo es lícito se convierta en una cosa mala por alguna circunstancia" (143).

Dicha cristianización supone, por supuesto, la anexión al imperio español. De allí que para Todorov "[h]ay una cosa segura: Las Casas no quiere que cese la anexión de los indios, simplemente quiere que la hagan religiosos en vez de soldados" (1992: 184). "La sumisión, y colonización, se debe mantener, pero hay que llevarlas de otra manera; no sólo ganarán con ello los indios (al no ser torturados y exterminados), sino también el rey y España" (185). Independientemente de las discusiones acerca de su personalidad y sus posiciones, de la visión contradictoria que se puede encontrar en la literatura acerca de él ${ }^{21}$, y los problemas que pueden verse en su argumentación, Bartolomé de las Casas ha pasado a la Historia como el gran defensor de los Indios, título que indesmentiblemente le pertenece por derecho: hará de la lucha contra la esclavitud de los indios el objetivo de su vida ${ }^{22}$. Vitórico Muñoz R. ha escrito con razón que "nunca, ningún otro autor que se ha referido a Nuestra América ha escrito con sangre y tinta, apasionada actitud y serena argumentación, emotiva defensa y horrorosa denuncia, los usos, abusos, estropicios, muerte y desolación que los españoles u otros semejantes realizaron sobre el Nuevo Mundo" (1999: 92). El reconocimiento de esta grandeza, sin embargo, no puede borrar el hecho evidente que la anexión de los indígenas al imperio español nunca fue criticada ni puesta en tela de juicio por el santo.

\section{INJURIA Y GUERRA JUSTA}

A juicio de Francisco de Vitoria el fundamento general de toda guerra que pueda ser calificada de "justa" y, por lo tanto, también de la guerra de con-

${ }^{21}$ Cf.: O’Gorman, 1993, y Menéndez Pidal, 1963.

${ }^{22}$ En este punto habrá que poner de manifiesto que Las Casas no fue el único defensor de los indios, su posición no era una postura aislada sino compartida por otros autores pertenecientes a lo que Fernando Mires ha llamado la "Inteligentzia clerical-indigenista" que parece haber constituido una suerte de "movimiento ideológico" o casi un "partido", según este autor (Cf.: Mires, 2006, 142ss). 
quista, es el haber recibido una "injuria" (1998: 173-175). Dicha injuria es la que permitiría, pese a reconocer ciertos límites ${ }^{23}$, lícitamente el dar muerte a los enemigos tanto durante como una vez terminado el combate si se lo estimara necesario para conseguir la paz y la seguridad (200-204), despojarlos de sus bienes (197) y reducirlos a la "cautividad y servidumbre" (199200). Una vez vencido el enemigo y terminada la guerra justa, el vencedor puede retener lo conquistado -ya sean bienes muebles o inmuebles-, lo que no significa, sin embargo, que el saqueo esté necesariamente permitido (205-209); puede, a su vez, imponer tributo a los enemigos vencidos (209) e incluso, en algunos casos justificados, llegar a deponer a los príncipes enemigos y reemplazarlos por otros o apoderarse directamente del gobierno (210). La guerra para Vitoria es siempre claramente una conquista. En efecto, si se considera la pregunta por las razones por las que se levantan las armas contra alguien, por una parte, la respuesta de Vitoria es, como se dijo, el haber sido injuriado. $\mathrm{Al}$ abordar la pregunta acerca de la finalidad que se persigue con ello, por otra parte, la respuesta, de acuerdo con Vitoria, es el afán de castigar y escarmentar a quien nos ha ofendido. Hacerle la guerra a quien nos ha ofendido está considerado, por lo tanto, como un castigo, de allí que el ofensor deba pagar con sus bienes, incluso con su libertad. Se trata de un castigo que tiene como fundamento principal la revancha, la venganza. Castigo que puede -incluso tal vez debe- ser impuesto por la fuerza de las armas, mediante una violencia justificada; una violencia como la de la ley. El castigo impuesto será, como se ve, el ser conquistado, saqueado, esclavizado.

Esta causa justa de la guerra -ser víctima de injuria- tiene en Vitoria su desarrollo en una serie de "justos títulos de conquista"24. Se trata de si-

\footnotetext{
${ }^{23}$ Entre los límites está el dar muerte a inocentes (niños y mujeres) directa e intencionadamente. Sobre este asunto Vitoria hace una serie de distinciones (Cf.: 193-197).

${ }^{24}$ Es importante recordar que Vitoria se encarga de enumerar y desautorizar a un grupo no menor de títulos de conquista a los que llama "Títulos no legítimos de la dominación". Éstos son: (1) que el emperador sea el señor del mundo y por lo tanto tenga derecho a ocupar y tomar posesión de los territorios de los bárbaros (pp. 87-96), (2) que el Papa sea señor del orbe, incluso temporal, por lo que pueda constituir como príncipes de los bárbaros a los reyes de España e imponerlos por la fuerza de existir oposición (pp. 96-105), (3) que las tierras descubiertas, pese a estar habitadas, sean de quien las encuentra (105-106), (4) que en caso de que los bárbaros se nieguen a recibir la fe, pese a habérseles propuesto y rogado insistente y pacíficamente, se le pueda obligar con violencia, mediante la guerra y el terror, a aceptarla, despojándolos a la vez de sus bienes (106-118), (5) que a causa de los pecados mortales de los bárbaros, que atentan contra la ley natural, deban ser atacados con las armas y sometidos por la fuerza (118-122), (6) que puesto que los bárbaros mismos han aceptado libre y voluntariamente ceder sus derechos a los españoles, éstos se harían dueños y señores (123), (7) que Dios hubiera condenado a los bárbaros por sus abominaciones y los haya entregado en manos de los españoles (123-124).
}

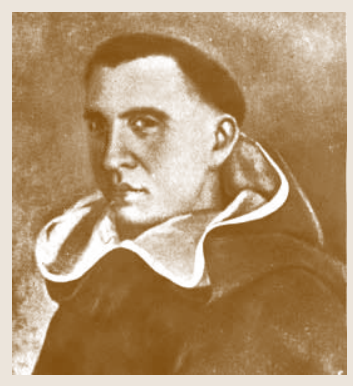

F. de Vitoria 
tuaciones puntuales en que, a su juicio, se da efectivamente una injuria que justifica o legitima la guerra de conquista: la violación del principio de la sociedad y comunicación natural: libertad de tránsito, de comercio, de participación de los bienes comunes, acceso a la ciudadanía (129-139); la resistencia al derecho de propagación de la fe cristiana, esto es, de predicaranunciar el Evangelio (139-143); la opresión y terror ejercido sobre los conversos para que vuelvan a la idolatría (143); la liberación de los cristianos conversos que se encuentran bajo el yugo de un señor infiel (144-145); la defensa de los inocentes que se encuentran bajo la tiranía y la opresión (145-146); la de proteger a quienes libre y voluntariamente eligen subordinarse al rey de España (146); la de defensa de los amigos y los aliados (147).

\section{A. Defensa y protección de los nuestros}

En la dinámica de la defensa, de la protección y de la liberación se mueven la gran mayoría de los Justos Títulos de Vitoria (4, 5, 6 y 7). No todo ellos se refieren, sin embargo, a los mismos sujetos que han de ser defendidos, protegidos o liberados: unos aluden a los conversos, otros a los oprimidos y otros a los súbditos voluntarios, amigos y aliados. No todas las situaciones, por lo tanto, son iguales, sin embargo, en principio se podría afirmar que la dinámica argumental -si se le puede llamar de esa forma- es la misma en todos los casos. Estos títulos tienen en común el hecho de que quien ha sido injuriado -el converso, los oprimidos, los súbditos voluntarios, los amigos y los aliados- no es a quien se le otorga el derecho de reaccionar ante dicha injuria. Quien toma venganza no es el ofendido. En todos los casos los injuriados son indígenas, indígenas que se han vuelto cristianos, que están siendo tiranizados por sus reyes, que han aceptado someterse al imperio español o que se declaran amigos o aliados de éstos. No son ellos, sin embargo, los que de acuerdo con estos títulos adquieren el derecho de reaccionar frente a la injuria que se les ha infringido. Son los españoles quienes adquieren un justo título para hacer la guerra y conquistar a aquellos que, sin haberlos injuriado en lo más mínimo, sin embargo, sí lo habrían hecho con los conversos, con los oprimidos, los súbditos voluntarios, los amigos y los aliados. Se puede observar que aquí opera una suerte de traspaso de derecho desde los ofendidos hacia los vengadores.

Se podría sostener, con Vitoria, que aquel que ha sido injuriado tiene un justo título para reaccionar; incluso se podría afirmar que tiene derecho para hacerlo con la fuerza de las armas si la injuria así lo amerita. De eso 
se trata la "legítima defensa", pero en estos casos que Vitoria trae a colación no es el injuriado mismo quien adquiere el justo título de reacción, sino los españoles. Sólo por esta simple razón es que no se puede hablar de estos títulos como si se tratara de "legítima defensa", puesto que, como es bien sabido, ella tiene requisitos taxativos muy estrictos, el primero de los cuales es que sea el ofendido, el injuriado, quien en justicia se defienda del agresor, del injuriador, y éste no es el caso en ninguno de los títulos de Vitoria ahora analizados. Hay, sin embargo, en casi todos los casos mencionados por el autor un vínculo, una ligazón entre el injuriado y los españoles: el compartir la fe cristiana, el ser súbditos del rey, el ser amigo o aliado. Esta vinculación podría, en principio, servir para explicar que los españoles tengan el derecho a intervenir. Un caso que en principio parece algo diferente es el de los oprimidos, pues allí no hay vínculo evidente -fuera del hecho de ser humanos-, sin embargo el desamparo de quien no puede defenderse por sí mismo permitiría operar el traspaso del derecho a la reacción hacia quien sí tiene el poder de hacerlo.

Este último caso permite constatar que en todas estar situaciones de defensa lo que ocurre es que el español adquiere el derecho a intervenir porque el sujeto que es víctima de una injuria no puede defenderse con sus propias manos. Dicho de otra forma, se trata en todos los casos, en el fondo, de uno y el mismo título: defensa del abusado, del injuriado, del oprimido, del violentado, que no puede defenderse por sí mismo. Defensa que se haría especialmente vinculante porque o bien se trata de cristianos igual que los españoles, o porque se han declarado libremente súbditos de la corona, o porque son amigos o aliados del imperio español o, simplemente, porque son seres humanos que no pueden defenderse de los abusos de que son objeto. Como sea, sin embargo, el título de fondo sigue siendo siempre el mismo: "defensa de los débiles". Dicha menesterosidad estaría en el fundamento del derecho que tendrían los españoles para intervenir en los asuntos de los indígenas. Con esto se estaría respondiendo a la pregunta que planteara Fernando Mires: “¿de dónde provenían los derechos de los españoles para inmiscuirse en los asuntos internos de otras naciones?" (Mires, 2006: 72). Lo que hace Vitoria con estos títulos es establecer excepciones para lo que se conoce hoy en derecho internacional como el principio de "no intervención".

La soberbia del autodenominado civilizado se pone de manifiesto aquí con toda nitidez. Tzvetan Todorov ha puesto claramente de manifiesto que la reciprocidad en este caso desaparece, pues aquí los españoles son "quienes decidieron el sentido de la palabra 'tiranía', y eso es lo esencial. Los es- 
pañoles, a diferencia de los indios, no son solo parte, sino también juez, puesto que ellos determinan los criterios según los cuales se habrá de emitir el juicio" (192-161). Los españoles son los que deciden, de hecho, en qué momento y de qué forma se ha cometido una injuria contra los indígenas -sean cristianos o no lo sean, sean amigos o no, sean súbditos o no- que amerita una intervención armada de su parte. Una vez más nos encontramos frente a un eurocentrismo, un hispanocentrismo flagrante: son los españoles quienes deciden, por los indígenas, cuando han sido ofendidos, y son ellos los llamados a tomar las acciones correspondientes, esto es, la venganza por medio de la guerra de conquista.

\section{B. Sociedad y comunicación natural}

El primero de los "Justos Títulos" para la conquista de Vitoria, el llamado "de la sociedad y comunicación natural", es, sin duda, de un tremendo alcance. No en vano ha pasado a constituir uno de los pilares del Derecho Internacional moderno. Este título se refiere a la existencia y eventual violación de cuatro derechos que le deben ser reconocidos a los españoles (nótese que Vitoria se refiere sólo a los españoles como depositarios de estos derechos): (1) el de "recorrer" los territorios de los bárbaros y permanecer en ellos (129), (2) el de "comerciar" con los bárbaros (132), (3) el de participar de los bienes comunes de los bárbaros (133) y (4) el de ciudadanía (134-135). El presupuesto de funcionamiento del título y, por lo tanto, su límite -en esto Vitoria será majadero- es que se dé "sin daño alguno para los bárbaros" (129), "sin injusticia ni daño" (130), "sin perjuicio para su patria" (132), "sin daño para los ciudadanos" (132), "con tal de que no se perjudique a los ciudadanos y naturales del país" (134). Los españoles tendrán que "demostrar por todos lo medios que no vienen a hacerles daño, sino que quieren residir allí pacíficamente y recorrer su territorio sin daño alguno para ellos" (136). Muy bien los derechos de paso, de establecimiento, de comercio, de participación y ciudadanía, pero siempre y cuando ellos no impliquen perjuicio alguno para los indígenas. Los conquistadores deberán demostrar "por todos los medios" con "razones y argumentos", "no solo con palabras sino con hechos" que es así, de lo contrario los derechos no serían exigibles.

La injuria que daría paso a una guerra justa se basa, de acuerdo con Vitoria, en estos dos supuestos: la existencia de los derechos y la falta absoluta de daño y perjuicio. Allí reside la injuria ejercida contra el extranje- 
ro que simplemente pretende transitar, instalarse o participar sin que ello implique ninguna consecuencia negativa para la nación receptora. “(...) los bárbaros, al prohibir a los españoles el ejercicio del derecho de gentes, les hacen injurias; luego si fuera necesario hacer la guerra para obtener su derecho, puede lícitamente hacerla" (136). Aunque Vitoria sólo se refiere a los derechos de los españoles respecto de los "bárbaros" (sólo a modo de ejemplo menciona el caso de la relación entre España y Francia), los derechos a los que hace alusión podrían eventualmente tener valor universal como normas de derecho internacional. Si este derecho de la sociedad de las comunicaciones esbozado por Vitoria tuviera una validez universal, sería indispensable, sin embargo, una total "reciprocidad", esto es, que los derechos se los reconocieran mutuamente españoles e indígenas. Si se tratara de un derecho universalmente válido, de hecho, todo pueblo, cada pueblo tendría el derecho al que Vitoria alude. En su discurso no hay pasaje alguno, sin embargo, en que el autor se refiera a que los españoles les reconozcan a los indios el derecho de paso, de permanencia, de participación y nacionalidad.

La razón que podría esgrimirse para fundamentar esta falta de reconocimiento, para continuar en la lógica de Vitoria, es el posible daño o perjuicio que ello ocasionaría a España, a los españoles, a su comercio, etc. El bien de España está primero. Con ello se salva la universalización del principio vitoriano, pero se ponen las bases para un nuevo problema: el del titular del derecho. Ahora bien, si España puede justamente expulsar a un extranjero, negarle el derecho a instalarse y participar de sus bienes comunes, si puede limitar el derecho a la nacionalidad amparada en el argumento de que la perjudicaría, entonces es España la que determina si un extranjero atenta o no contra ella, si es un peligro, si debe evitar que traspase siquiera sus límites. En este mismo esquema, no importa cuantos gestos haga el bárbaro para demostrar que su intervención sería inocua, que tiene intenciones pacíficas, que su permanencia no afectará en nada la marcha normal del país, podrá echar mano de "razones y argumentos", de "palabras y de hechos", pero si los españoles lo juzgan potencialmente dañino le negarán con todo derecho, para usar una terminología más contemporánea, la visa. Quien evalúa la inocencia e inocuidad de un extranjero, por lo tanto, es el país receptor, para nuestro caso, los habitantes de las Indias y no los españoles. ¿Por qué habría de constituir una injuria, por lo tanto, el que los indígenas limiten el ejercicio de estos derechos a los españoles? Los conquistadores pueden hacer todos los gestos que quieran para demostrar su "buena fe"; quienes deben juzgar si ello es ajustado o no a la realidad son los indígenas y no los españoles, por lo que tienen todo el derecho, todavía en el marco 
de la argumentación vitoriana, de negarles el derecho a pisar siquiera su territorio, sin que ello constituya, ahora en contra de Vitoria, una injuria, sino simplemente el ejercicio de su derecho de soberanía.

En todo caso, este título de Vitoria -así lo ponen de manifiesto los relatos de Bartolomé de las Casas y otros- da cuenta de una enorme inocencia o ceguera, pues de hecho los españoles que llegan al Nuevo Mundo no tenían para nada la intención de no afectar la situación encontrada, ya sea por medio de las armas en busca de riquezas o mediante la evangelización en busca de nuevos feligreses (139). Su permanencia no pretendía ser, en ningún caso, inocua, y les correspondía a los habitantes originarios evaluar como positivo o negativo ese cambio que venían a provocar los extranjeros. Es perfectamente posible, y ajustado a la argumentación vitoriana, el sostener que los indígenas podían considerar dañina la presencia y el paso de los españoles por sus tierras -tanto de los conquistadores como de los evangelizadores- y por lo tanto, tenían pleno derecho de negarles la entrada a las tierras americanas.

Finalmente, la argumentación de Vitoria, aludiendo a todos sus títulos, se diluye al ser contrastados con la realidad de lo ocurrido en el Nuevo Mundo. La pregunta que podría plantearse es: ¿dónde está la tremenda injuria que los indígenas habrían cometido contra los cristianos que justifica la conquista y la esclavitud, la destrucción y el horror de un genocidio? Antes bien, fueron los indios quienes luego de abrir su tierra, sus casas y sus corazones a los recién llegados, fueron ofendidos, agraviados, asesinados. Bartolomé de las Casas escribía que “(...) nunca los indios de todas las Indias hicieron mal alguno a los cristianos, antes los tuvieron por venidos del cielo, hasta que primero, muchas veces, hubieran recibido de ellos o sus vecinos muchos males, robos, muertes, violencias y vejaciones de ellos mismos" (1999: 79). La causa justa se desplaza, por lo tanto, tal como lo viera Las Casas, hacia los indios. “(...) y sé por cierta e infalible ciencia, que los indios tuvieron siempre justísima guerra contra los cristianos, y los cristianos, una ni ninguna nunca tuvieron justa contra los indios" (88).

\section{CONCLUSIONES}

Son varios los aspectos de la llamada "filosofía de la conquista" que se han querido destacar en este trabajo. En primer lugar, el hecho que aunque hay autores que sustentan posiciones diferentes, incluso antagónicas, todas comparten, sin embargo, la idea de que los indígenas deben ser incorpo- 
rados al mundo europeo, a su cosmovisión, a su religión, que deben ser civilizados y evangelizados. Ni la corriente más extremadamente esclavista e imperialista representada tan claramente en el pensamiento de Juan Ginés de Sepúlveda, pero tampoco la visión indigenista encarnada en la reflexión de Bartolomé de las Casas, eran, de hecho, anticolonialistas. El destino de vasallaje, de subordinación de los indígenas al imperio nunca estuvo realmente en discusión. La "filosofía de la conquista" se sustenta sobre las dicotomías civilizados-bárbaros, y cristianos-infieles. Dicotomías que se concretizan en una evidente sobrevaloración del modo de vida español y una minusvaloración de la de los habitantes originarios de América. La "filosofía de la conquista" constituye, en realidad, un intento por fundamentar la legitimidad del domino español sobre las Indias, por justificar el gesto radical e indetenible de hacer de América otra España. Desde esta perspectiva es eminentemente una filosofía hegemónica, una filosofía "para" la conquista. Juan Ginés de Sepúlveda, Francisco de Vitoria y Bartolomé de las Casas, aunque difieren radicalmente en sus postura, tienen en común el eurocentrismo y el colonialismo; el convencimiento de la superioridad del mundo europeo-cristiano y de una inferioridad de los indígenas, para los cuales el camino de la colonización y la evangelización es un ascenso, un evidente mejoramiento, la ruta hacia la civilización y el reino de Dios.

\section{REFERENCIAS}

Aristóteles. 1994. Política. Manuel García Valdés (trad.). España: Gredos.

Dussel, Enrique. 1977. Filosofía de la liberación. Argentina: Edicol.

García, Antonio. 1984. "El sentido de las primeras denuncias", La ética de la conquistas en América, Francisco de Vitoria y la Escuela de Salamanca, Corpus Hipanorum de Pace, Tomo XXV. Madrid: Consejo Superior de Investigaciones Científicas, pp. 67-115.

Friede, Juan. 1974. Bartolomé de las Casas, precursor del anticolonialismo. México: Siglo XXI.

García-Pelayo, Manuel. 1996. "Juan Ginés de Sepúlveda y los problemas jurídicos de la Conquista de América" (Introducción), en Ginés de Sepúlveda, Juan. Tratado sobre las justas causas de la guerra contra los indios. México: FCE.

Ginés de Sepúlveda, Juan. 1996. Tratado sobre las justas causas de la guerra contra los indios. México: FCE.

Hanke, Lewis. 1967. La lucha española por la justicia en la conquista de América. Madrid: Aguilar.

Las Casas, Bartolomé de. 1942. Del único modo de atraer a todos los pueblos a la verdadera religión. México: FCE. 
1957. Historia de las Indias. Madrid: Biblioteca de Autores Españoles, Libro Y.

. 1999. Brevísima relación de la destrucción de Indias. Madrid: Cátedra.

López de Gómara, Francisco. [1941] 1963. Historia general de las Indias, tomo II. Madrid.

Menéndez Pidal, Ramón. 1963. El padre Las Casas, su doble personalidad. Madrid: Espasa-Calpe.

Mires, Fernando. 2006. En nombre de la cruz. Discusiones teológicas y politicas frente al holocausto de los indios. Argentina: Libros de Araucaria.

Muñoz G., Vitórico. 1999. "Fray Bartolomé de Las Casas como paradigma de la filosofía latinoamericana”, Cuadernos Americanos № 75, pp. 92-101.

O’Gorman, Edmundo. 1993. "Hacia una nueva imagen del padre Las Casas", prólogo de Los indios de México y Nueva España. México: Porrúa.

Pérez Tudela, Juan. 1957. "El significado histórico de la vida y escritos del padre Las Casas”, Estudio crítico preliminar, en Las Casas, Bartolomé, Historia de las Indias. Madrid: Biblioteca de Autores Españoles.

Todorov, Tzvetan. 1992. La conquista de América: el problema del otro. España: Siglo XXI.

Vitoria, Francisco de. 1998. "Relección primera. Sobre los Indios recientemente descubiertos", Sobre el poder civil, Sobre los indios, Sobre el derecho de guerra. Madrid: Tecnos, pp. 55-150. . 1998. "Relección segunda. Sobre los Indios o sobre el derecho de la guerra de los españoles sobre los bárbaros”, Sobre el poder civil, Sobre los indios, Sobre el derecho de guerra. Madrid: Tecnos, pp. 151-212.

Zavala, Silvio. [1947] 1994. Filosofía de la conquista. México: FCE. 